\title{
Just Around the Corner: The Future of U.S. Public Transportation
}

\author{
Steven E. Polzin \\ University of South Florida
}

Nearly 40 years ago when I was contemplating my first full-time job offer from a highly regarded transit agency, many folks told me what an exciting time it was for public transportation, as we were "just around the corner" from a revolution and renaissance. Growth, urbanization, fuel availability and price concerns, environmental sensitivities, and a growing reluctance to presume that urban roadway expansion could meet travel needs provided a logical basis for such prognostications. The compelling appeal of the personally owned automobile has repeatedly been underestimated - there was no turning point. Transit's relative role in terms of market share faded through the mid-1970s, followed by fluctuations and a modest overall growth trend in total ridership but slightly declining per capita use. More recently, the recessionary increase in ridership has been offset by decline during the recent economic recovery.

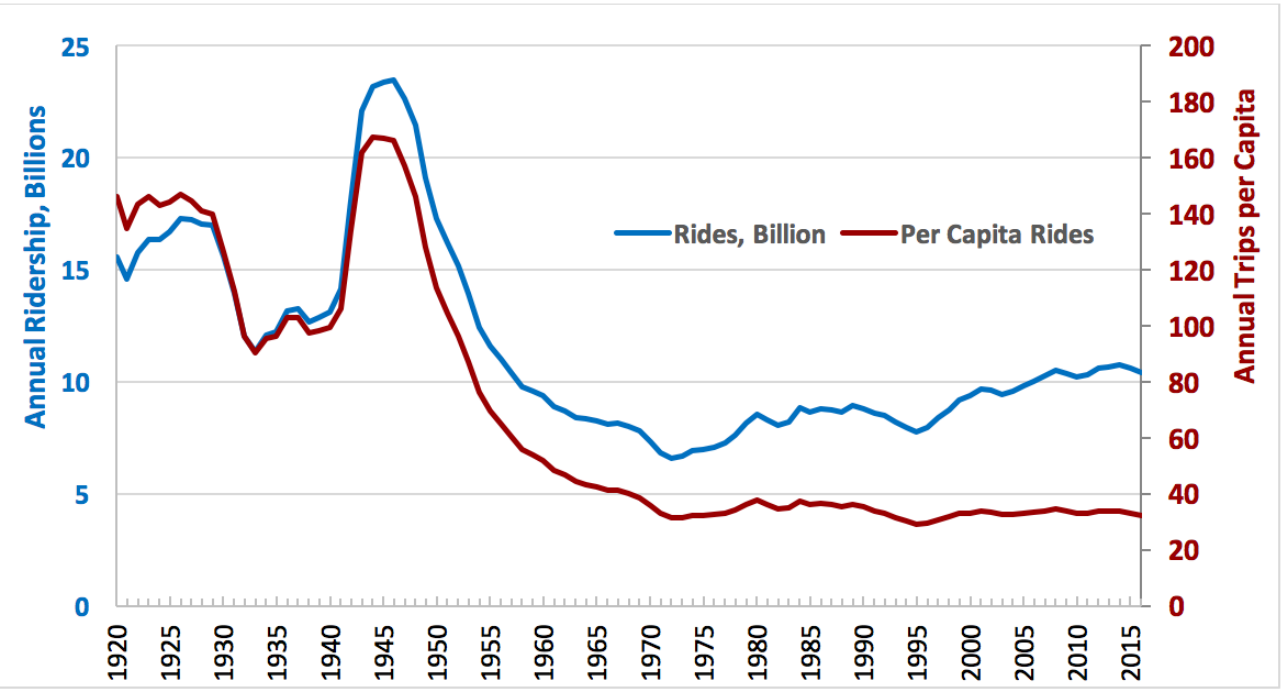

FIGURE 1.

U.S. Transit Ridership and Ridership/Capita Trends ${ }^{1}$

'Population-1920-1989, U.S. Census Historical Estimates; 1990-2009, National Intercensal Tables; 2010-current, National Population Totals Tables. Ridership-1920-2012, APTA's Public Transportation Fact Book (Appendix A); 2013-current, APTA's Ridership Report Archives.

(C) 2018 Steven E. Polzin

http//dx.doi.org/10.5038/2375-0901.21.1.5

ISSN: 1077-291X | Licenced under Creative Commons License Attribution - Noncommercial 4.0

The Journal of Public Transportation is published by the Center for Urban Transportation Research at the University of South Florida 
All transportation, including public transportation, is changing, and we may have now come to that corner. However, we still do not know how sharp that corner will be or what is around it. A wealth of perspectives exists. The history of transportation and public transportation is integrally related to demographic and development trends, transportation technology trends, and economic and governance trends. All these factors are currently in play. In particular, the prospect of lower urban travel costs by shared vehicle use, shared travel via transportation network companies (TNCs), and ultimately by automated vehicles suggests a dramatic transformation in personal travel, especially in urban areas, and public transit as we know it. Individuals using shared vehicles own fewer or no vehicles and pay for trips. Automated vehicles could reduce travel costs for those willing to have the vehicle pick up and drop off other passengers while traveling toward their destination. Thus, discussions about the future of public transit are extraordinarily timely and important to position stakeholders to help shape that future.

It would be easy to fill many pages forecasting the future of public transportation; however, the comments herein are bound by considering three key goals that underlie the provision of public transportation:

1. Provide transportation to enable upward mobility and enhanced quality of life for those unable to provide their own mobility.

2. Provide a resource-efficient means of moving people.

3. Stimulate economic development and influence land use.

Although these goals do not encompass fully the motivations for providing public transportation infrastructure and services, they capture the core incentives that have led to the public's willingness to invest resources in public transportation. Stakeholders remain engaged and public transit continues to provide the means for addressing any number of public concerns going forward. However, by focusing on goals that characterize public transportation as we know it today, the future of public transportation is framed in the context of how various goals will be pursued rather than how institutional structures or service delivery technologies might be changing.

Indeed, the challenge and opportunity for public transit is to transition such that the core motivations for providing public transportation continue to be aspirations for transportation planners and decision makers. Public transit as we know it today is unlikely to exist in the future. What will exist is the need to have transportation options that meet the needs of those who are unable to provide mobility for themselves, options that offer resource-efficient means of moving volumes of people, and options that complement other collective aspirations of our society, such as economic opportunity and the productive deployment of capital and human talents. Today's governance and funding arrangements for public transportation may change markedly, and the technologies that characterize public transportation today (bus, heavy rail, light rail, streetcar) may no longer dominate the perception of what public transportation is. 
Several decades in the future, some elements of our current public transportation infrastructure will probably be in use. Many exclusive guideway corridors likely will continue providing high-volume services to major travel markets by trains of vehicles, perhaps still running on rails. Vehicles will have automated operation, although the pace of positive train control (PTC) implementation might make us wonder how quickly things can change in the transit infrastructure arena. Shorter-life, roadway-based transportation technologies for moving travelers will likely evolve faster with the very real prospect of mobility options offered by myriad different-sized, technology-enhanced vehicles. Who owns, operates, and regulates these services remains to be seen, although government will likely remain a significant stakeholder. Various vehicle sizes and ownership/operations/governance frameworks responsible for ensuring the availability of mobility options may well continue. The governance and funding silos that differentiate public transit from personal vehicle use today may disappear as historic technology, funding, and governance aspects of modal definitions are no longer distinguishable, or become too diverse to categorize. Technology changes-but not just technology changes-guarantee that the future will differ from the present.

\section{The Future of Public Transit as a Social Service}

Arguably, the most important role for public transportation is to provide mobility options for those without the ability to secure transportation at market rates. The 2016 American Community Survey (ACS) indicates that, on average, $8.7 \%$ of U.S. households do not have a personal auto available (U.S. Census Bureau 2016). It is unknown how many are carless by choice, but most are a result of physical or mental health conditions, financial considerations, or legal constraints. National Household Travel Survey (NHTS) data indicates that $48.5 \%$ of transit trips are made by persons from households with no vehicle available (Chu 2012). Onboard survey data compiled by the American Public Transportation Association (APTA) indicates that $33.0 \%$ of all transit trips and $46.0 \%$ of bus transit trips are made by individuals whose household incomes are below $\$ 25,000$ annually (APTA 2017). Thus, the availability of public transportation enables a significant share of the population to have the mobility that supports their quality of life by virtue of the fact that local, state, and federal governments have invested in transit services and facilities.

When thinking about the future of public transportation in the context of this social service role, a number of potential issues arise. In the United States, virtually $100 \%$ of the capital cost of public transit investments and approximately $70 \%$ of transit operating costs are supported by revenue sources other than passenger fares (FTA 2016). Thus, travelers using public transportation have their mobility highly subsidized. In addition, certain groups meet other eligibility criteria such that their fares are reduced and/or supported by other agencies' resources. Looking ahead, technology offers a number of possible changes in transportation access and affordability. Automated self-driving vehicles, for example, offer the potential of making travel options available to persons with mental and physical disabilities who are unable to operate a personal vehicle. Individuals who may not be constrained by resources but are transit travelers by virtue of their inability to 
operate vehicles would have a new travel opportunity, no longer depending on traditional fixed-route or paratransit service providers. Even today, TNCs such as Uber and Lyft offer greater convenience and a lower price point than previously offered by taxi services. Transit agencies are experimenting with various TNC partnerships serving paratransit trips, transit access and egress, and target area circulation markets. The independence of being able to solicit a vehicle in real time via an app offers a pronounced enhancement in personal mobility for many.

Another segment of individuals who use public transportation because personal vehicle use is financially challenging may have a lower-cost travel opportunity through technologyenabled vehicle sharing and/or ride sharing. Various speculative analyses suggest that per-passenger-mile costs for using shared automated vehicles might be well below current levels for operating personal vehicles. U.S. average auto operating costs in the range of $\$ 0.50-\$ 0.60$ per passenger mile are higher than various predictions of costs for automated mobility services, estimated to deliver transportation for $\$ 0.20-\$ 0.50$ per passenger mile or less if shared (Arbib and Seba 2017). Additionally, mobility service costs are structured as marginal per-trip costs and therefore are more palatable than the fixed-cost nature and lumpiness of the vehicle purchase, registration, and insurance costs that characterize auto ownership and can drive personal vehicle use costs to very high levels. This is particularly the case for individuals who incur these fixed costs but travel modest amounts over which to amortize the costs in expensive urban markets. The emergence of mobility services that can provide per-trip costs in a price range below auto ownership costs would allow additional individuals to rely on market-based transportation options, implicitly reducing the market for traditional fixed-route transit services.

However, the poorest of the poor still may need some mechanism of financial support to avail themselves of mobility. This mobility is critical to health care, education, and employment, and therefore is critical to the quality of life and upward mobility opportunity. Historically this has meant reliance on publicly operated or publicly procured transit services and low or subsidized fares. In the future, this might mean continued reliance on traditional transit services or, alternatively, accommodating this market's mobility needs via user subsidies for publicly or privately operated mobility services. For example, analogous to the Supplemental Nutrition Assistance Program (SNAP), eligible individuals might receive a subsidy to purchase market-priced mobility services.

Generally, government social services are intended to meet the needs of individuals who, for various reasons, are unable to meet those needs without assistance. The government does not necessarily aspire to enlarge participation in programs such as SNAP or programs to support housing, phones, or utilities; indeed, declines in the use of these programs would be celebrated by most as a sign that economic conditions have enabled more people to provide for their own needs. Such logic might suggest that the recent softness in transit ridership coincident with the economic recovery and growing employment should be celebrated, as the economic recovery means more people are able to provide their own mobility and are less reliant on public transportation. Thus, from the perspective of meeting the mobility needs of those dependent on transit, reduced ridership resulting from improved economic conditions and/or the availability 
of alternative affordable options could be considered positive and an opportunity to minimize public expenditures coincident with declining need.

\section{The Future of Public Transit as a Resource-Efficient Means of Moving People}

The prospect of less public transportation due to economic conditions reducing the need and/or technology enhancements enabling alternative options at lower price points runs headlong into the second fundamental goal of public transportation-providing a resourceefficient means of moving people. High volume and high utilization of assets and services are generally required for transit to accomplish its goal of resource efficiency, such that critical resources of fuel, infrastructure, labor, and urban space are used productively. More modest demand from those dependent on public transportation jeopardizes the resultant levels of service remaining sufficiently attractive to significant numbers of travelers who have choices, given our predominately many-to-many urban travel patterns.

Looking ahead, a number of evolving trends may fundamentally change at least some aspects of the resource efficiencies of various modes of travel. First, from the perspective of energy efficiency and the highly correlated vehicle emissions, two fundamental trends are in play. A historic virtue of urban rail transit has been that it is usually propelled by electrical energy and, hence, has no on-site vehicle emissions and has the opportunity to be powered by non-carbon fuel sourced energy. Currently, approximately one-third of transit passenger miles comprise heavy and light rail passengers riding electrically powered vehicles (APTA 2016). The inclusion of electrified regional and commuter rail would push the share of electrically powered passenger miles even higher. The movement toward electric buses will result in larger shares of public transit travelers riding electrically propelled vehicles. However, simultaneously, the movement toward electrically powered personal vehicles, if it succeeds, will result in mitigating or neutralizing public transit's historic competitive advantage with respect to fuel source and emissions.

Perhaps more relevant, the relative modal efficiency in terms of energy utilization has shifted over time and may continue to do so. Due to modest utilization in U.S. operations, bus-based public transportation has consumed more BTUs per passenger mile than has automobile travel for a number of years (Davis et al. 2016). Similarly, modest utilization of rail systems also jeopardizes their energy efficiency claims. Based on 2014 data, heavy rail carries 27.1 passenger miles per car mile of service, whereas light rail carries 23.8. Based on reported electrical use, heavy rail systems are delivering mobility at $0.208 \mathrm{kWh}$ per passenger mile and light rail systems at $0.377 \mathrm{kWh}$ per passenger mile (APTA 2016). For perspective, web sources report a Tesla Model $\mathrm{S}$ consumes approximately $0.33 \mathrm{kWh}$ per vehicle mile (Noland 2014). Occupancies higher than 1.0 in personal vehicles or consideration of smaller electric personal vehicles would further influence the energy efficiency comparisons of traditional public transit versus personal vehicles. If data for New York, Chicago, and some of the other highly productive older rail systems in the densest markets were excluded, the comparisons would be even more discouraging. 
Resource efficiency also involves the physical space requirements for providing mobility. Not only does the physical space of transportation infrastructure incur costs for purchasing right-of-way, but also space efficiency enables more intensive development patterns that offer the opportunity to capture agglomeration benefits by virtue of enhanced accessibility while simultaneously minimizing overall travel. Public transportation large-vehicle modes always have had a competitive advantage by delivering higher volumes of people with more modest requirements for both travelway space and vehicle storage/parking. Looking ahead, two anticipated considerations will come into play. First, the prospect of automated shared vehicles dramatically reduces the space requirements for vehicle storage and allows that space to be shifted away from locations where it consumes valuable land, such as the cores of central business districts. Various scenarios envision substantial urban space being freed up by reduced parking requirements enabling a significant intensification of development should markets materialize to take advantage of that space (Chapin et al. 2016). Second, various scenarios of automated vehicle deployment envision substantial increases in the throughput of travelways (Polzin 2017). Engineers attribute throughput increases to several characteristics of technology-enhanced vehicles, including:

- reductions in incident delays by virtue of safer vehicles

- increased capacity via smoother vehicle flow

- optimized dynamic intersection operation

- reduced following distances

- narrower lanes by virtue of smaller vehicles and precise travel path management, and

- reduced vehicle numbers due to ride sharing (higher vehicle occupancies).

Although these considerations will be unlikely to produce throughput per lane comparable to the highest-volume peak-period of heavily utilized rail corridors, such volumes are relevant only in a limited set of intensively developed urban corridors.

Another critical resource to consider is money or cost. Speculating on the competitive costs of future mobility options and their supporting infrastructure is beyond the scope of this paper, and such data are unavailable beyond speculation. However, the magnitude of changes in system efficiencies, infrastructure requirements, and the scale economies of various elements of infrastructure and technology might well be altered significantly. There is the prospect of scaling vehicle sizes to match demands and optimizing vehicle capacity to meet market needs. Similarly, there is the prospect of offering high-performance services to public transit or multi-occupant vehicles integrated within a travelway that also carries personal vehicles and commercial vehicles-reducing the need for exclusive infrastructure to ensure congestion-free operation and enabling greater utilization and infrastructure cost sharing across market segments. For transit to remain competitive going forward, planners must be sensitive to scaling the investments to market size so that the cost per unit of mobility delivered is competitive. 


\section{The Future of Public Transit as a Tool to Stimulate Economic Activity and Influence Land Use}

A frequently cited goal or benefit of public transportation is its ability to influence land use nearby and stimulate economic activity in the region. Indeed, deploying resources collected from a broader geography or time period on a specific project in a specific location at a given point in time can stimulate economic activity in that vicinity. The stimulus effect of transit investment comes from two major factors. First, the expenditure of resources on labor and materials stimulates economic activity in the target location. Thus, a given location benefits, but those resources are drawn from other geographies or other points in time (debt financing) where the extraction of those funds would be expected to have a drag effect on economic activity. The overall net impact may be modest or neutral, but the non-uniformity of investment confers benefits to the areas receiving those resources.

The second stimulus on economic activity is associated with the prospect that improved transportation offers improved mobility that can be leveraged through lower time and money transportation costs and agglomeration economies realized by businesses with access to a larger labor force, which can optimize staffing and workforce synergies and, hence, enhance productivity. The improved mobility is accomplished both by the investment in transportation capacity and by the fact that public transportation can encourage densification along corridors, thus minimizing travel distances.

Looking ahead, changes in technology as applied to transportation may influence the magnitude and value of economic development associated with transportation investment. As noted, the prospect of enhanced capacity for existing infrastructure systems may enable society to capture the benefits of agglomeration if market forces alter land development patterns to either use freed-up parking space or take advantage of increased capacity in roadway systems enabled by self-driving vehicles. In addition, continued improvements in communication, the prospects of things such as drone deliveries, and trends such as growing participation in work-at-home programs may alter the fundamental relationship between productivity and activity concentration.

The relationship between transportation investment and economic development is nuanced and conditional (Polzin 1999). Irrespective of mode, improvements in transportation that alter travel time and money costs will continue to affect development, economic activity, and quality of life. Going forward, one of the challenges for planners will be to determine which transportation improvement investments produce the most mobility improvement and subsequent economic impact. At some level, public transit investments may have to compete with a host of other transportation investments outside of the funding silos that exist today. Capturing economic development benefits will be premised on targeting investments for those improvements that offer the biggest mobility benefit. And perhaps the cost of mobility improvements can be more directly ascribed to those who gain the economic and development benefits of that investment. 


\section{Summary}

The natural tendency among those associated with public transportation will be reluctance to let go of the institutional structures, systems, and services that exist today. Yet, the magnitude of technology and other changes envisioned suggests that a more prudent focus may be to ensure that the core motivations for today's transit services are well articulated and advocated so as to remain critical considerations in the future. Specifically, enhancing mobility - particularly for those who are unable to provide it for themselvesshould remain a critical consideration in this new frontier of transportation. Irrespective of institutional structure and technologies, society will benefit by ensuring that travel options are available and affordable for all segments of society. Indeed, technology may help us more effectively attribute cost to beneficiaries and target subsidies to those truly in need. The mechanism or mechanisms by which these services are delivered may change substantially, and the model of the service operator may change over time. The public interest may be in ensuring that mobility options are available and that those most in need have the resources to take advantage of these options. That may or may not mean today's transit agencies directly operating or procuring those services.

Similarly, America has struggled with the conflicting goals of wanting to enhance mobility while simultaneously wanting to mitigate the negative externalities of travel. This issue has been an important factor in favoring public transportation, as it historically has been safer, more energy-efficient, and less land-intensive. The concern of minimizing the impacts of travel will continue, but the solutions may be very different. The ultimate goal should be to ensure that the negative externalities of providing mobility are not borne disproportionately and are minimized with respect to the benefits that mobility provides to society. Historical perceptions of the resourceintensiveness of various means of travel need to be revisited, as new technologies and operating conditions are clearly changing historic relationships. Technology potentially neutralizes differential safety benefits across modes and electrification with the prospect of sustainable electric production in the future. Additionally, a spectrum of vehicle sizes targeted to market needs will neutralize emissions and energy consumption considerations across modes and minimize the relevance of this factor in transportation policy and investment considerations. Other impacts such as noise and environmental and social disruption caused by the physical presence of transportation facilities similarly might be altered as technologies change the features and externalities of transportation, and technology enables significantly higher capacity within existing transportation corridors.

Of course there will be challenges and impacts, but changes create the opportunity to have better and less impactful transportation options in the future. The stakeholders for public transportation have an opportunity to advocate for the core motivations that have resulted in today's public transportation services, while still recognizing that future solutions might differ with respect to institutional structure, technologies, services, governance, and funding. Transportation can become more available and less impactful.

\section{References}


APTA. 2016. Public Transportation Fact Book 2016, Appendix A. Washington, DC: American Public Transportation Association.

APTA. 2017. Who Rides Public Transportation. Washington, DC: American Public Transportation Association.

Arbib, J., and T. Seba. 2017. Rethinking Transportation 2020-2030. A RethinkX Sector Disruption Report. Retrieved from https://static1.squarespace.com/ static/585c3439be65942f022bbf9b/t/591a2e4be6f2e1c13df930c5/1494888038959/ RethinkX+Report_051517.pdf

Chapin, T., L. Stevens, J. Crute, J. Crandall, A. Rokyta, and A. Washington. 2016. Envisioning Florida's Future: Transportation and Land Use in an Automated Vehicle World. Florida State University Department of Urban \& Regional Planning. Florida Department of Transportation Report \#BDV30 TWO 934-10.

Chu, X. 2012. An Assessment of Public Transportation Markets Using NHTS Data. National Center for Transit Research, University of South Florida. Florida Department of Transportation Report \#BDK85 977-17.

Davis, S. C., S. W. Diegel, and R. G. Boundy. 2016. Transportation Energy Data Book: Edition 35, ORNL-6992. Oak Ridge, TN: Oak Ridge National Laboratory.

FTA. 2016. 2015 National Transit Summary and Trends. Washington, DC: Office of Budget and Policy, Federal Transit Administration.

Noland, D. 2014. "Life with Tesla Model S: One Year And 15,000 Miles Later." Green Car Reports. Retrieved from https://www.greencarreports.com/news/1090685_life-with-tesla-model-sone-year-and-15000-miles-later

Polzin, S. 2017. Vehicle Miles Traveled Trends and Implication for the U.S Interstate Highway System. White Paper. Center for Urban Transportation Research, University of South Florida.

Polzin, S. E. 1999. "Transportation/Land-Use Relationships: Public Transit's Impact on Land Use." Journal of Urban Planning and Development, 125(4). doi: 10.1061/(ASCE)07339488(1999)125:4(135)

U.S. Census Bureau. 2016. American Community Survey. Retrieved from https://www.census. gov/programs-surveys/acs/data.html

\section{About the Author}

Steven Polzin, Ph.D. (polzin@cutr.usf.edu) is the Program Director of Mobility Policy Research at the Center for Urban Transportation Research at the University of South Florida. His research concentrates on travel behavior, public transportation, travel data analysis, and transportation decision making. His current research explores future travel demand and the implications of technology on travel behavior, including the impact of transportation network companies and autonomous/connected vehicles. In 2016, Dr. Polzin was named a Top 10 Transportation Thought Leader in Academia by the Eno Center for Transportation. 
Just Around the Corner: The Future of U.S. Public Transportation

He teaches graduate courses on Transportation and Land Use and Public Transportation. Dr. Polzin is a civil engineer with a BSCE from the University of Wisconsin-Madison, and master's and doctorate degrees from Northwestern University. 